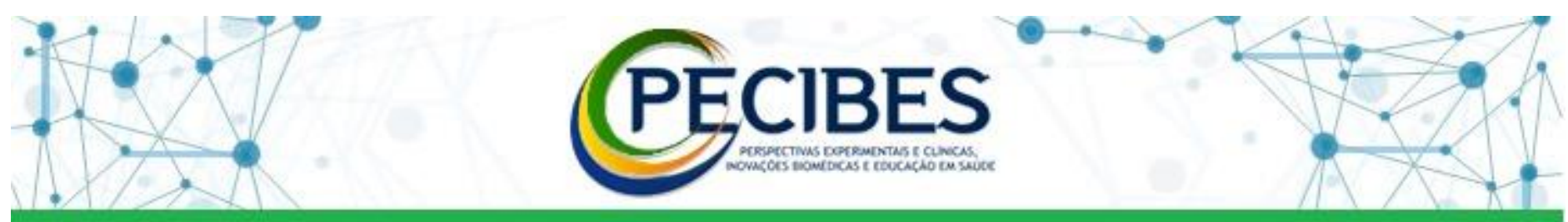

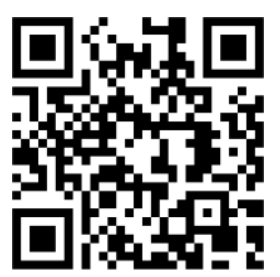

http://www.seer.ufms.br/inde x.php/pecibes/index

\begin{abstract}
* Autor correspondente: Cristiano Rafael Moré, Universidade Federal de

Mato Grosso do Sul UFMS. E-mail do autor: crmore80@gmail.com
\end{abstract}

Descritores: Corridas. Desempenho. Atividade condicionante. Saltos..

Key-words: Races. Performance. Conditioning activity. Jumps.

\section{Influência da intensidade na potenciação do salto pós-corrida em corredores recreacionais vs. indivíduos fisicamente ativos}

Influence of intensity on post-running jump potentiation in recreational runners vs. physically active individuals

Cristiano Rafael Moré ${ }^{1}$, Rita Adriana Stoeterau Moré ${ }^{1}$, Eduardo Feijó da Rocha ${ }^{1}$, Daniel Boullosa ${ }^{1}$, Rodolfo André Dellagrana ${ }^{1}$.

1. Educador físico. Universidade Federal de Mato Grosso do Sul, Campo Grande/MS, Brasil.

\section{Eixo Temático: Atenção Multiprofissional em Atividade física, Reabilitação e Desempenho Físico-Funcional}

Resumo

INTRODUÇÃO: O aumento de desempenho pós-ativação (Post-activation performance enhancement - PAPE) é uma melhora aguda no desempenho de exercícios físicos após uma atividade condicionante máxima ou submáxima. O PAPE tem sido associado a indivíduos treinados, e parece sofrer influência do nível de condicionamento e intensidade da atividade condicionante. Entretanto, não está claro a influência da intensidade no PAPE em corridas de endurance em indivíduos com diferentes níveis de condicionamento físico. OBJETIVO: Verificar o efeito de duas corridas, com diferentes intensidades no PAPE pós-corrida, em indivíduos com níveis de condicionamento físico distintos. MÉTODOS: Dezoito homens, divididos em dois grupos de 9 corredores recreacionais $(34,5 \pm 9,3$ anos; $73,1 \pm 11,9 \mathrm{Kg}$; $1,76 \pm 0,06 \mathrm{~m} ; 17,4 \pm 4,4 \%$ de gordura; $16,4 \pm 1,0 \mathrm{Km} . \mathrm{h}-1 /$ velocidade aeróbica máximaVAM), e 9 indivíduos fisicamente ativos $(34,1 \pm 9,4$ anos; 83,2 $\pm 7,7 \mathrm{Kg} ; 1,79 \pm 0,06 \mathrm{~m}$; $25,6 \pm 5,4 \%$ de gordura; $13,3 \pm 1,2 \mathrm{Km} . \mathrm{h}-1 / \mathrm{VAM}$ ) realizaram saltos com contra movimento $(\mathrm{CMJ})$ pré e pós corridas de diferentes intensidades. Os participantes realizaram um teste máximo incremental (University Montreal Track Test - UMTT) para determinar a VAM e distância a ser completada nas intervenções (70\% da VAM vs. tempo limite - Tlim). A interação do CMJ com o tempo, intervenção e grupo foi analisada por uma ANOVA de três vias. Projeto aprovado pelo CEP-UFMS, registro CAAE: 44522821.4.0000.0021, parecer: 4.676.873 de 28 de Abril de 2021. RESULTADOS:Foi identificada diferença significativa no tempo $(F=10,716 ; p<0,01)$ e na interação corrida vs. grupo $(F=12,094 ; p<0,01)$, com aumento da altura do CMJ em $6,8 \%$ pós-corrida $70 \%$ da VAM nos indivíduos fisicamente ativos e $6 \%$ após o Tlim nos corredores. CONCLUSÃO: O efeito no desempenho do CMJ foi maior após um teste máximo nos corredores e após um protocolo submáximo nos indivíduos fisicamente ativos, indicando que a intensidade da atividade condicionante pode influenciar no desempenho de acordo com o condicionamento físico. 